\title{
WISATA HALAL: POTENSI EKONOMI BARU INDUSTRI PARIWISATA DI KABUPATEN CIREBON
}

\author{
Eva Siti Ropiah ${ }^{1}$ \\ Email : evasitiropiah@gmail.com
}

\begin{abstract}
The tourism industry is a collection of inter-related tourism businesses to meet the demand of foreign tourists and domestic tourists, an increase in the number of tourists is an economic potential of a region. One tourism industry is halal tourism. Halal tourism is a journey that is done with the intention of being grateful for what God has created, so that in its implementation the Islamic Shari'a is implemented with the aim of increasing faith. Cirebon Regency PAD in 2017 amounted to 779,337.85 million rupiah. Tourism sector in Cirebon Regency in 2017 has an effect of 2.3\%. In 2017 tourist arrivals increased from the previous year, which was 713,591 people. Economic potential for halal tourism in Cirebon Regency can be seen from pilgrimage, culinary, culture that can continue to be developed into a lucrative economic potential especially with the support of the government and other elements such as academics and practitioner.
\end{abstract}

Keywords: Tourism Industry, Local Goverment Revenue, Halal Tourism

\begin{abstract}
ABSTRAK
Industri pariwisata merupakan kumpulan usaha wisata yang saling terkait untuk memenuhi permintaan wisatawan asing maupun wisatawan domestik, peningkatan jumlah wisatawan merupakan potensi ekonomi suatu daerah. Salah satu industri wisata adalah wisata halal. Wisata halal merupakan perjalanan yang dilakukan dengan niat mensyukuri apa yang telah Allah ciptakan, sehingga dalam pelaksanaannya syariat-syariat Islam diterapkan dengan tujuan untuk meningkatkan keimanan. PAD Kabupaten Cirebon pada tahun 2017 sebesar 779.337,85 juta rupiah. Sektor Pariwisata di Kabupaten Cirebon pada tahun 2017 berpengaruh sebesar 2.3\%. Tahun 2017 kunjungan wisatawan meningkat dari tahun sebelumnya, yaitu 713.591 orang. Potensi ekonomi pada wisata halal di Kabupaten Cirebon dapat dilihat dari wisata ziarah, kuliner, budaya yang dapat terus dikembangkan menjadi suatu potensi ekonomi yang menggiurkan terlebih dangan adanya dukungan pemerintah serta elemen lainnya seperti akademisi maupun praktisi.
\end{abstract}

Kata Kunci: Industri Pariwisata, PAD, Wisata Halal

\footnotetext{
${ }^{1}$ Mahasiswa Pascasarjana IAIN Syekh Nurjati Cirebon.
} 
INKLUSIF Vol 3. No. 2 Desember 2018

\section{PENDAHULUAN}

\section{A. Latar Belakang}

Tren wisata halal semakin berkembang seiring meningkatnya populasi muslim dunia, siaran pers Kemenpar yang dikutip oleh Sakti menerangkan bahwa pada GMTI 2018 peringkat Indonesia naik menjadi peringkat kedua sejajar dengan Uni Emirat Arab. ${ }^{2}$ Sementara Malaysia bertahan pada peringkat pertama. Menteri Pariwisata Arief Yahya menegaskan bahwa pada tahun 2019 Indonesia harus meraih peringkat pertama pada GMTI selanjutnya dengan target 5 juta wisatawan mancanegara muslim dan 242 juta wisatawan nusantara muslim, mengingat negara ini adalah negara dengan populasi muslim terbanyak di dunia. Top-9 peringkat destinasi wisata halal pada tahun 2018 berdasarkan studi GMTI 2018 secara berurutan adalah Malaysia, Uni Emirat Arab dan Indonesia, Turki, Arab Saudi, Singapore, Qatar, Bahrain, Oman, terakhir Maroko. Tahun ini Iran tidak termasuk dalam kategori 10 negara terbaik dalam destinasi wisata halal terbaik versi GMTI 2018 tergantikan oleh negara Singapore.

Serupa dengan GMTI, Indonesia meluncurkan Indonesia Muslim Travel Index (IMTI) pada tanggal 5 Juni 2018 dengan tujuan untuk menentukan peringkat destinasi - destinasi di Indonesia yang paling ramah terhadap wisatawan muslim dengan berbagai kriteria yang sudah ditetapkan. ${ }^{3}$ Peluncuran program Indonesia Muslim Travel Index (IMTI) merupakan kerjasama Kemenpar dengan Crescentrating - Mastercard. Program ini juga menjadi pemicu untuk memenangkan destinasi wisata halal terbaik dunia versi GMTI pada tahun 2019 yang akan datang. Menpar Arief Yahya menjelaskan, GMTI paling dikenal di seluruh dunia sehingga GMTI 2019 menjadi ajang untuk 'menjual' Indonesia di kancah Internasional agar dikenal dunia sebagai destinasi wisata moslem friendly kelas dunia.

Tourism Review, dalam Widadyo menjelaskan bahwa konsep wisata syariah/wisata halal adalah sebuah proses pengintegrasian nilai-nilai kelslaman kedalam seluruh aspek kegiatan wisata. Nilai syariat Islam sebagai suatu kepercayaan dan keyakinan yang dianut umat muslim menjadi acuan dasar dalam membangun kegiatan pariwisata. ${ }^{4}$ Wisata syariah mempertimbangkan nilai-nilai dasar umat Islam di dalam penyajiannya mulai dari akomodasi, restaurant, hingga aktivitas wisata yang selalu mengacu kepada norma-norma kelslaman.

Adannya industri pariwisata syariah bukanlah suatu ancaman bagi industri pariwisata yang telah berjalan sebelumnya, melainkan sebagai pelengkap dan tidak menghambat kemajuan usaha wisata yang sudah ada. Bahkan sejumlah negara-negara di dunia telah menggarap industri pariwisata syariah. Peran Kementrian Pariwisata dan Ekonomi Kreatif sangatlah penting sebagai penyokong utama terbentuknya wisata halal yang relevan sehingga bisa sejajar dengan negara lain yang memiliki destinasi wisata halal. Dalam otonomi daerah, wisata halal menjadi salah satu $P R$ bagi bidang pariwisata setiap daerah agar terus dikemas sebaik dan semenarik mungkin untuk menarik wisatawan. Bidang pariwisata di Kabupaten/Kota

\footnotetext{
${ }^{2}$ Guntur Sakti, “Siaran Pers: Indonesia Berada Di Peringkat 2 Global Muslim Trvel Index 2018," 2018, kemenpar.go.id.

${ }^{3}$ Guntur Sakti.Guntur Sakti, "Siaran Pers : Menpar: Berada Di Peringkat I GMTI, Wisata Halal Indonesia Akan Mudah Rebut Pasar Global," 2018, kemenpar.go.id.

"Kurniawan Gilang Widagyo, “Analisis Pasar Pariwisata Halal Di Indonesia,” The Journal of Tauhidinomics, 2015.
} 
Cirebon yang merupakan satu wadah di dalam Dinas Kebudayaan, Pariwisata, Pemuda dan Olahraga (Disbudparpora) tengah berencana dalam pengembangan wisata halal, mengingat sebelumnya Cirebon terkenal dengan wisata religinya.

Indonesia menyiapkan 13 (tiga belas) provinsi yang dijadikan destinasi wisata halal, yakni NusaTenggara Barat (NTB), Nangroe Aceh Darussalam, Sumatera Barat, Riau, Lampung, Banten, DKI Jakarta, Jawa Barat, Jawa Tengah, Yogyakarta, JawaTimur, Sulawesi Selatan, dan Bali. ${ }^{5}$ Wilayah tujuan wisata tersebut ditentukan berdasarkan kesiapan sumber daya manusia, budaya masyarakat, produk wisata daerah, serta akomodasi wisata. Salah satu daerah di Jawa Barat, Cirebon, merupakan wilayah potensial dalam pengembangan wisata halal. Wilayah yang berada di daerah pesisir laut jawa ini terbagi menjadi dua, yaitu kabupaten dan kota. Luas Kabupaten Cirebon 990,36 $\mathrm{km}^{2}$ dengan total kepadatan penduduknya sekitar 2.957.257 jiwa yang tinggal di 40 kecamatan. Jumlah penduduk beragama Islam di Kabupaten Cirebon berdasar statistik Jawa Barat adalah 2.024.157. Luas wilayah dan penduduk mayoritas muslim di Kabupaten Cirebon menjadikan potensi wisata halal besar peluangnya.

Kabupaten Cirebon tidak hanya dikenal dengan wisata kuliner dan religinya yang kental, tetapi juga menawarkan kekayaan alam yang cukup banyak dan bagus. ${ }^{6}$ Selain itu, Kabupaten Cirebon memiliki desa wisata yang identik dengan pembuatan gerabah serta rotan. Disana wisatawan bisa belajar membuat gerabah juga rotan. Desa yang terkenal dengan pembuatan gerabahnya yang memiliki nilai estetika tinggi adalah Desa Sitiwinangun, di desa tersebut diperkenalkan cara membuat gerabah dengan pengeringan yang relatif cepat yaitu hanya sekitar 45 menit. Sedangkan desa yang terkenal dengan kerajinan rotannya adalah Desa Sindangwangi, berbagai kerajinan dari rotan dibuat sehingga memiliki bentuk yang unik dan menarik, wisatawan juga dapat belajar langsung membuat kerajinan tersebut.

Pada umumnya manusia bertindak rasional dalam mempertimbangkan jenis informasi yang tersedia dan mempertimbangkan segala resiko yang timbul dari tindakannya sebelum melakukan sebuah perilaku tertentu, begitu halnya dengan mempertimbangkan informasi mengenai suatu destinasi wisata, wisatawan mempertimbangkan hal tersebut untuk mengunjunginya. Belum adanya regulasi pemerintah Kabupaten Cirebon mengenai wisata halal tentu berdampak pada industri pariwisata di Kabupaten Cirebon. Pada dasarnya wisatawan muslim mengunjungi suatu destinasi wisata halal yang sudah jelas sertifikasinya sehingga mereka tidak ragu lagi untuk melakukan kunjungan ke tempat yang mereka inginkan.

Wisatawan dapat memilih destinasi wisata halal berdasarkan keunggulan yang dimiliki oleh setiap destinasi yang berbeda. Dalam pemasaran wisatawan diasumsikan sebagai konsumen yang memilih produk berupa jasa dari destinasi wisata halal. Dalam hal ini, industi pariwisata memiliki peranan penting bagi pemenuhan kebutuhan wisatawan. Dalam bab 1 pasal 1 Undang-Undang Republik Indonesia dijelaskan bahwa industri pariwisata merupakan sekumpulan usaha pariwisata yang terkait dalam rangka menghasilkan barang maupun jasa.

\footnotetext{
${ }^{5}$ Kemenparekraf, “Kajian Pengembangan Wisata Syariah," 2015.

${ }^{6}$ Muhamad Irzhal Adia Kurnia, "Tak Hanya Religi, Ini Wisata Menarik Lainnya Di Kabupaten Cirebon,” 2017, https://travel.kompas.com/read/2017/05/13/120700727/tak.hanya.religi.ini.wisata.menarik.lainnya.di.kabupaten.cir ebon.
} 
Melihat potensi wisata halal yang dijelaskan di atas, Jaelani dalam papernya yang berjudul Islamic Tourism Development In Cirebon: The Study Heritage Tourism in Islamic Economic Perspective menjelaskan bahwa Cirebon akan menghadapi persoalan mengenai pariwisata syariah, terutama fasilitas yang disediakan ${ }^{7}$. Persoalan mengenai parwisata syariah menjadi hal yang patut diperhatikan karena akan berpengaruh terhadap kunjungan wisatawan serta industri pariwisata yang ada. Selain itu, dampaknya juga akan terlihat jika dinilai dari perspektif ekonomi Islam, mengingat wisata halal merupakan wisata yang baru berkembang di Cirebon. Berdasarkan latar belakang yang telah diuraikan diatas, maka terdapat beberapa permasalahan sebagai berikut: Bagaimana kondisi ekonomi di Kabupaten Cirebon? Bagaimana gambaran pariwisata di Kabupaten Cirebon? Bagaimana proyeksi potensi ekonomi pada wisata halal di Kabupaten Cirebon?

\section{B. Metode Penelitian}

Penelitian ini menggunakan pendekatan penelitian kualitatif. Sumber data yang diambil dalam penelitian ini adalah sumber data primer dan sumber data sekunder. Dalam hal ini, peneliti mengambil data primer melalui hasil wawancara dengan bidang pariwisata Disbudparpora Kabupaten Cirebon. Adapun sumber data sekunder diperoleh peneliti selama melaksanakan studi kepustakaan, berupa literatur maupun data tertulis yang berkenaan dengan penelitian. Peneliti dalam hal ini mengambil data sekunder melalui BPS Kabupaten Cirebon, profil Disbudparpora dan laporan-laporan yang berkaitan dengan data yang diperlukan seperti pada BPS Kabupaten Cirebon, Laporan Akuntabilitas Kemenpar 2017. Teknik pengumpulan data yang digunakan dalam penelitian ini adalah menggunakan observasi, wawancara, dan dokumentasi.

\section{PEMBAHASAN}

\section{A. Kondisi Ekonomi di Kabupaten Cirebon dilihat dari PAD Kabupaten Cirebon dan Rasio Kemandirian Fiskal}

Tabel

Realisasi Pendapatan Pemerintah Kabupaten Cirebon 2016-2017 (juta rupiah)

\begin{tabular}{|l|l|c|c|}
\hline \multirow{2}{*}{$\begin{array}{l}\text { Jenis Pendapatan / Source of } \\
\text { Revenues }\end{array}$} & \multicolumn{2}{|c|}{2016} & 2017 \\
\cline { 2 - 4 }$(1)$ & $(2)$ & $(3)$ \\
\hline $\begin{array}{l}\text { Pendapatan Asli Daerah } \\
\text { (PAD)/Original Local } \\
\text { Government Revenue }\end{array}$ & $\mathbf{5 2 9 . 0 5 0 , 2 9}$ & $\mathbf{7 7 9 . 3 3 7 , 8 5}$ \\
\hline & $\begin{array}{r}\text { Pajak Daerah/Local Taxes } \\
\text { Retribusi Daerah/Retributions }\end{array}$ & $158.183,20$ & $186.141,91$ \\
\hline & $38.818,70$ & $40.173,84$ \\
\hline
\end{tabular}

${ }^{7}$ Aan Jaelani, "Islamic Tourism Development In Cirebon: The Study Heritage Tourism in Islamic Economic Perspective," 2016, 1-24, http://www.researcherid.com/rid/D-6905-2016. 
INKLUSIF Vol 3. No. 2 Desember 2018

\begin{tabular}{|c|c|c|}
\hline $\begin{array}{l}\text { Hasil Pengelolaan Kekayaan } \\
\text { Daerah yang Dipisahkan/ } \\
\text { Income of Regional Gov. } \\
\text { Corporate and Management } \\
\text { of Separated Reg. Gov.Wealth }\end{array}$ & $6.387,45$ & $7.215,26$ \\
\hline $\begin{array}{l}\text { Lain-lain PAD yang Sah/Other } \\
\text { Original Local Gov. Revenue }\end{array}$ & $325.660,94$ & $545.806,84$ \\
\hline $\begin{array}{l}\text { Dana Perimbangan/Balanced } \\
\text { Budget }\end{array}$ & 2.158.776,17 & $2.074 .515,21$ \\
\hline $\begin{array}{l}\text { Bagi Hasil Pajak dan Bagi Hasil } \\
\text { BukanPajak/Sumber Daya } \\
\text { Alam/Tax Sharing and Non } \\
\text { Tax/Natural Resources Sharing }\end{array}$ & $77.429,55$ & $71.262,84$ \\
\hline $\begin{array}{l}\text { Dana Alokasi Umum/General } \\
\text { Allocation Funds }\end{array}$ & $22.024,73$ & $26.620,36$ \\
\hline $\begin{array}{l}\text { Dana Alokasi Khusus/Special } \\
\text { Allocation Funds }\end{array}$ & $1.521 .877,11$ & $1.495 .142,63$ \\
\hline Dana Lainnya/Others Funds & $537.444,78$ & $481.489,38$ \\
\hline $\begin{array}{llr}\text { Lain-lain } & \text { Pendapatan } & \text { Daerah } \\
\text { yang } & \text { Sah/Other } & \text { Legal } \\
\text { Revenue } & & \end{array}$ & $674.585,98$ & $737.690,02$ \\
\hline Jumlah/Total $(1+2+3)$ & $3.362 .412,44$ & $3.591 .543,08$ \\
\hline
\end{tabular}

Berdasarkan tabel di atas dapat terlihat bahwa PAD Kabupaten Cirebon pada tahun 2016 sebesar 529.050,29 juta rupiah. Sedangkan pada tahun 2017 sebesar 779.337,85 juta rupiah. Berdasarkan rumus rasio kemandirian fiskal, akan dicari rasio kemandirian fiskal Kabupaten Cirebon pada tahun 2016-2017. Rasio ini digunakan sebagai ukuran tingkat ketergantungan daerah terhadap bantuan pihak ekstern (terutama Pemerintah Pusat dan Provinsi), rumus yang digunakan sesuai dengan yang dijelaskan sebelumnya:

$$
\text { Rasio Kemandirian }=\frac{P A D}{\text { Bantuan Pusat, Provinsi \& Pinjaman }} \times 100 \%
$$




$$
\begin{gathered}
\text { Rasio kemandirian } 2016=\frac{529.050,29 \text { juta rupiah }}{674.585,98 \text { juta rupiah }} \times 100 \% \\
\text { Rasio kemandirian } 2016=78 \%
\end{gathered}
$$

$$
\begin{gathered}
\text { Rasio kemandirian } 2017=\frac{779.337,85 \text { juta rupiah }}{737.690,02 \text { juta rupiah }} \times 100 \% \\
\text { Rasio kemandirian } 2017=105 \%
\end{gathered}
$$

Berdasarkan hasil perhitungan di atas dapat dinyatakan bahwa kedua tahun tersebut memiliki pola hubungan delegatif, yaitu campur tangan Pemerintah Pusat sudah tidak ada karena daerah telah benar-benar mandiri dalam melaksanakan otonomi daerah karena hasil perolehannya di atas $75 \%$.

\section{B. Gambaran Pariwisata di Kabupaten Cirebon}

Kabupaten Cirebon yang sebagian wilayahnya terletak di sepanjang pantai laut Jawa menjadikan daerah ini didiami oleh berbagai karakteristik budaya, yaitu budaya asli daerah, budaya luar maupun percampuran keduanya. Sebagian lagi wilayah Kabupaten Cirebon berada di daerah perbukitan sehingga makin beragamlah karakteristik yang ada dan ini merupakan suatu modal untuk kemajuan daerah. Di sini pengaruh pembangunan dan modernisasi berdampak jelas terhadap perubahan kehidupan politik, ekonomi, sosial, budaya serta pertahanan dan keamanan, terlebih Kabupaten Cirebon merupakan pintu gerbang memasuki wilayah Provinsi Jawa Tengah.

Tidak hanya budaya yang kental, tetapi wisata religi di Cirebon cukup kental dengan adanya makam Sunan Gunung Jati, mengingat Cirebon sendiri merupakan salah saru wilayah yang menjadi sejarah penyebaran agama Islam di tanah Jawa, dan Sunan Gunung Jati adalah salah satu dari sembilan wali yang menyebarkan agama Islam. Kabupaten Cirebon ditetapkan sebagai destinasi wisata pilgrimage (ziarah) dan cagar budaya sesuai dengan kesepakatan bersama antara gubernur dengan bupati/walikota nomor 912/05/Bapp tentang prioritas pembangunan ekonomi wilayah koordinasi perencanaan pembangunan di Jawa Barat. ${ }^{8}$ Lokasi wisata ziarah di Kabupaten Cirebon adalah:

\section{Wisata ziarah makam Sunan Gunung Jati}

Obyek wisata ini berada di Desa Astana Kecamatan Gunung Jati. Kawasan wisata ziarah Gunung Jati. Lokasi ini merupakan tujuan wisata religi, Sunan Gunung Jati dengan areal mencapai $\pm 20 \mathrm{Ha}$. Makam Sunan Gunung Jati tidak hanya menjadi obyek wisata, tetapi obyek ini juga sudah ditetapkan menjadi cagar budaya yang harus dilindungi.

\section{Wisata ziarah Kramat Talun}

Obyek wisata ini merupakan tempat peristirahatan sesepuh Cirebon, Mbah Kuwu Cirebon Girang. Obyek wisata ini berada di Desa Cirebon Girang Kecamatan Talun. Obyek wisata

${ }^{8}$ Bappelitbangda Kabupaten Cirebon, “Rencana Pembangunan Jangka Menengah Daerah (RPJMD) Kabupaten Cirebon 2014-2019," n.d. 48. 
ini telah ditetapkan sebagai cagar budaya yang dilindungi. Pengunjung obyek wisata ini berasal dari lokal, dan regional Jawa.

3. Wisata ziarah makam Syech Magelung Sakti

Obyek wisata ziarah ini berada di Desa Karangkendal Kecamatan Kapetakan. Pengunjung obyek wisata ini berasal dari lokal dan regional Jawa Barat.

\section{Wisata ziarah makam Nyi Mas Gandasari}

Obyek wisata ziarah ini berada di Desa Panguragan Kecamatan Panguragan. Pengunjung obyek wisata ini berasal dari lokal dan regional Jawa Barat.

Selain wisata ziarah yang disebutkan di atas, terdapat wisata lainnya, yaitu wisata alam. ${ }^{9}$ Kabupaten Cirebon memiliki sumber daya alam yang dapat dikembangkan menjadi obyek pariwisata alam. Lokasi wisata alam adalah:

\section{Wisata alam Gronggong dan Ciperna}

Gronggong memiliki ketinggian sekitar \pm 50 meter dpl dengan suasana alam yang menarik. Pada ketinggian ini, pengunjung dapat menikmati pemandangan suasana kota Cirebon dan pesisir Cirebon. Obyek wisata ini berada di jalur Cirebon-Kuningan. Secara administratif berada di Desa Patapan Kecamatan Beber. Fasilitas sarana dan prasarana yang mendukung obyek wisata ini adalah hotel, losmen, restoran, rumah makan, pusat kesegaran jasmani, padang golf, dan areal lesehan alam terbuka.

\section{Wisata alam Setu Patok}

Obyek wisata ini berada di Desa Setu Patok Kecamatan Mundu. Wisata alam ini berpotensi untuk dikembangkan sebagai areal pemancingan, pemandian, dan outbond. Situ Patok, dengan ciri khas berupa panorama alam, rekreasi air dan pemancingan dengan luas lahan mencapai \pm 7 ha.

\section{Wisata alam Plangon}

Obyek wisata ini berada di Kelurahan Babakan Kecamatan Sumber. Obyek wisata ini memiliki sumber daya alam satwa monyet dan petilasan Pangeran Kejaksan dan Pangeran Panjunan. Lokasi ini telah ditetapkan sebagai cagar alam yang dilindungi. Luas taman rekreasi plangon ini adalah $10 \mathrm{Ha}$.

\section{Wisata Alam Belawa}

Obyek wisata ini berada di Desa Belawa Kecamatan Sedong. Obyek wisata ini memiliki sumber daya alam satwa unik berupa labi-labi. Lokasi ini telah ditetapkan sebagai cagar alam yang dilindungi.

\section{Wisata Banyu Panas}

Obyek wisata ini berada di Desa Palimanan Barat, Kecamatan Gempol berupa wisata pemandian air panas yang kaya akan kandungan belerang. Obyek wisata Banyu Panas ini merupakan daya tarik yang berkembang seiring pengembangan sarana prasarana wisata di lokasi dan promosi wisata.

\footnotetext{
${ }^{9}$ Bappelitbangda Kabupaten Cirebon. 49.
} 
INKLUSIF Vol 3. No. 2 Desember 2018

\section{Situ Sedong}

Situ Sedong mempunyai ciri khas berupa panorama indah yang dikenal dengan Situ Pengasingan, rekreasi air, pemancingan, dan kebun mangga. Luas lahan situ ini mencapai $\pm 62,5 \mathrm{Ha}$.

Beberapa potensi wisata di atas dapat dijadikan nilai tambah (value added) pada wisata halal di Kabupaten Cirebon. Berdasarkan hasil wawancara dengan kepala bidang pariwisata Kabupaten Cirebon bahawa belum ada regulasi wisata halal di Kabupaten Cirebon, tetapi pada tahun 2017 Kabupaten Cirebon pernah mengikuti salah satu pelatihan wisata halal. Pelatihan dari bagian Provinsi yang menyelenggaran pelatihan khusus wisawata halal, sebagai persiapan daerah dalam destinasi wisata halal. ${ }^{10}$ Berdasarkan keterangan beliau, sebenarnya prinsipnya sama antara kabupaten dan kota Cirebon, tidak ada pemisahan batas wilayah dalam pariwisata yaitu tujuan akhirnya untuk meningkatkan kesejahteraan masyarakat. Contohnya one day tour Cirebon, Trusmi menjadi salah satu tujuan, kemudian keraton, dan lain sebagainya. Hanya saja di Kabupaten Cirebon belum ada biro perjalanan khusus wisata halal. Menurut beliau, wisata di Cirebon pasti halalnya karena jika melihat icon kota wali, para pelaku industri tidak akan sembarangan dalam hal makanan maupun hal lain yang tidak sesuai dengan aturan Islam.

Bidang Pariwisata Disbudparpora Kabupaten Cirebon juga memliki banyak event yang setiap tahunnya selalu ditargetkan sebagai event wajib seperti kirab budaya, nadran dan pesta laut, nok kacung dan lain sebagainya. Berbagai event yang disiapkan ini diharapkan menjadi salah satu alasan setiap wisatawan berkunjung dan tertarik dengan pariwisata yang ada di Kabupaten Cirebon.

Jaelani dalam penelitiannnya yang berjudul Event and festival in Cirebon: Review of shariah marketing mix menjelaskan banyak tujuan mengenai beberapa serangkain kegiatan yang terdapat di Cirebon sehinggga layak dijadikan salah satu destinasi wisata halal. Jaelani membagi kedalam lima kelompok event dan festival serta tujuan diadakannya event dan festival tersebut. yaitu event dan festival religi dan tradisi, seni dan budaya lokal, kuliner, keindahan alam, dan ekonomi. ${ }^{11}$

1. Event dan festival religi Nadran dan Sedekah Bumi Masyarakat Desa Gunung jati bertujuan untuk Pelestarian aset budaya wisata tahunan yang melibatkan berbagai elemen sebagai promosi obyek wisata serta sebagai ritual syukuran masyarakat Gunungjati kepada Allah SWT agar hasil panen dan tangkapan ikan lebih baik lagi.

2. Fashion Carnival, Cirebon Festival sebagai event seni dan budaya yang bertujuan:

a. Promosi kepariwisataan Cirebon untuk meningkatkan jumlah kunjungan parawisatawan.

b. Promosi jenis wisata baru yang berkualitas dan magnet entertaiment bagi wisatawan.

c. Menunjang pertumbuhan ekonomi kreatif yang berbasis keunggulan lokal.

\footnotetext{
${ }^{10}$ Edwin, “Hasil Wawancara Dengan Kepala Bidang Pariwisata Disbudparpora Kabupaten Cirebon,” 2018.

${ }^{11}$ Aan Jaelani, "Event and Festival in Cirebon: Review of Shariah Marketing Mix," Management, no. 6461 (2007), https://doi.org/10.1111/j.1574-0862.2010.00507.x/abstract.
} 
3. Event dan festival kuliner yang diselenggarakan di Asrama Haji Watubelah bertujuan untuk pelestarian kuliner Kabupaten Cirebon serta Peningkatan kreativitas dan inovasi masyarakat dalam membuat makanan olahan dengan bahan baku dari buah-buahan dan sayuran.

4. Gebyar Penghijauan dalam Rangka Rintisan Pengembangan Wisata Alam dan Sejarah Bukit Manengteung (Ajimut) sebagai salah satu event yang meunjukkan keindahan alam bertujuan untuk Penghijauan dan perintisan dalam pengembangan wisata alam dan wisata sejarah bukit Ajimut, dan meningkatkan minat baca masyarakat.

5. Event ekonomi lokal yang terdisi dari berbagai event, seperti:

a. Lomba Desain Rotan yang bertujuan untuk:

1) Meningkatan motivasi para pelaku industri rotan dalam inovasi desain produksi rotan yang berkualitas serta peningkatan daya saing industri rotandi Kabupaten Cirebon yang kompetitif di pasar internasional dan domestik.

2) Pengembangan industri mebel dan kerajinan rotan agar menghasilkan produk berkualitas, berdaya saing global dan berwawasan lingkungan.

3) Mewujudkan Kampung Wisata Rotan di Galmantro, di Desa Tegalwangi Cirebon.

b. Pemilihan Nok Kacung Kabupaten Cirebon yang bertujuan untuk Peningkatan peran pemuda (Nok dan Kacung) sebagai Duta Wisata pelestarian budaya lokal, serta promosi potensi wisata di Kabupaten Cirebon.

c. Batik Fashion Carnaval dan Pameran Kepariwisataan yang bertujuan untuk Promosi kepariwisataan, khususnya batik dan penguatan Kabupaten Cirebon sebagai tujuan wisata. Serta perumusan agenda tahunan pariwisata di Jawa Barat.

\section{Proyeksi Potensi Ekonomi Pada Wisata Halal di Kabupaten Cirebon}

1. Realisasi Pendapatan Pajak Hotel, Rumah Makan serta Hiburan di Kabupaten Cirebon 2016-2017

Tabel

Realisasi Pendapatan Pajak Hotel Kabupaten Cirebon 2016-2017 (juta rupiah)

\begin{tabular}{|l|l|r|r|}
\hline & \multicolumn{1}{|c|}{ Uraian Pajak Hotel } & \multicolumn{1}{c|}{$\mathbf{2 0 1 6}$} & \multicolumn{1}{c|}{$\mathbf{2 0 1 7}$} \\
\hline & Hotel Bintang Empat & $2.427,60$ & $2.644,84$ \\
\hline & Hotel Bintang Tiga & $1.257,90$ & 710,42 \\
\hline & Hotel Bintang Dua & 394,27 & 329,68 \\
\hline & Hotel Melati Tiga & 242,08 & 434,16 \\
\hline & Hotel Melati Dua & 57,82 & 55,50 \\
\hline & Hotel Melati Satu & 96,57 & 113,38 \\
\hline & $\begin{array}{l}\text { Losmen/rumah } \\
\text { penginapan/hotel/rumah kos }\end{array}$ & 159,08 & 160,79 \\
\hline \multicolumn{2}{|c|}{ Total pendapatan pajak } & $\mathbf{4 . 6 3 5 , 3 2}$ & $\mathbf{4 . 4 4 8 , 7 7}$ \\
\hline
\end{tabular}

Sumber: Badan Pengelolaan Pendapatan Daerah Kabupaten Cirebon 2018 (data diolah) 
Berdasarkan tabel di atas dapat terlihat bahwa pendapatan pajak daerah dari hotel di Kabupaten Cirebon pada tahun 2016 adalah sebesar 4.635,32 juta rupiah, menurun pada tahun 2017 yaitu sebesar 4.448,77 juta rupiah. Pendapatan pajak hotel tertinggi pada tahun 2016 pada hotel bintang empat yaitu sebesar $2.427,60$ juta rupiah, begitu halnya pada tahun 2017 yaitu 2.644,84 juta rupiah. Sedangkan pendapatan pajak hotel terendah pada tahun 2016 sebesar 57,82 juta rupiah pada hotel melati dua, sama halnya dengan yang terendah pada tahun 2017 yaitu htel melati dua sebesar 55,50 juta rupiah.

Tabel

Realisasi Pendapatan Pajak Restoran Kabupaten Cirebon 2016-2017 (juta rupiah)

\begin{tabular}{|l|l|r|r|}
\hline \multicolumn{1}{|c|}{ Uraian } & \multicolumn{1}{|c|}{$\mathbf{2 0 1 6}$} & \multicolumn{1}{c|}{$\mathbf{2 0 1 7}$} \\
\hline & Restoran & $4.280,33$ & $5.282,30$ \\
\hline & Rumah Makan & $2.527,66$ & $3.222,70$ \\
\hline & Café & 274,31 & 306,32 \\
\hline & Kantin & 136,37 & 98,31 \\
\hline & Catering & $2.510,44$ & $3.066,57$ \\
\hline & Jasa Boga & 476,03 & 596,42 \\
\hline \multicolumn{2}{|c|}{ Total pendapatan pajak } & $\mathbf{1 0 . 2 0 5 , 1 6}$ & $\mathbf{1 2 . 5 7 2 , 6 0}$ \\
\hline
\end{tabular}

Sumber: Badan Pengelolaan Pendapatan Daerah Kabupaten Cirebon 2018 (data diolah)

Berdasarkan tabel di atas dapat terlihat bahwa total pendapatan pajak daerah dari restoran di Kabupaten Cirebon pada tahun 2016 adalah 10.205,16 juta rupiah, sedangkan pada tahun 2017 sebesar 12.572,60 juta rupiah dengan pendapatan tebesar pada dua tahun tersebut sama yaitu pada restoran, tahun 2016 sebesar 4.280,33 juta rupiah dan tahun 2017 sebesar 5.282,30 juta rupiah. Pendapatan pajak terendah pada tahun 2016-2017 terdapat pada kantin yaitu tahun 2016 sebesar 136,37 juta rupiah dan pada tahun 2017 sebesar 98,31 juta rupiah.

Tabel

Realisasi Pendapatan Pajak Hiburan Kabupaten Cirebon 2016-2017 (juta rupiah)

\begin{tabular}{|l|l|r|r|}
\hline \multicolumn{1}{|c|}{ Uraian } & \multicolumn{1}{|c|}{$\mathbf{2 0 1 6}$} & \multicolumn{1}{c|}{$\mathbf{2 0 1 7}$} \\
\hline & Pagelaran kesenian & 23,47 & 7,00 \\
\hline & Karoke & 356,01 & 371,81 \\
\hline & Sirkus/Akrobat/Sulap & 134,10 & 37,35 \\
\hline & Permainan Bilyard & 2,10 & 2,10 \\
\hline & Permainan Ketangkasan & 477,13 & 476,47 \\
\hline & Pusat Kebugaran & 90,56 & 66,16 \\
\hline & Total pendapatan pajak & $\mathbf{1 . 0 8 3 , 3 0}$ & $\mathbf{9 6 0 , 9 0}$ \\
\hline
\end{tabular}

Sumber: Badan Pengelolaan Pendapatan Daerah Kabupaten Cirebon 2018 (data diolah) 
Berdasarkan tabel di atas dapat terlihat bahwa total pendapatan pajak daerah dari hiburan di Kabupaten Cirebon pada tahun 2016 adalah 1.083,30 juta rupiah sedangkan tahun 2017 menurun menjadi 960,90 juta rupiah.

\section{Kontribusi Pajak Hotel, Rumah Makan serta Hiburan terhadap Pendapatan Asli Daerah di Kabupaten Cirebon 2016-2017}

Berdasarkan realisasi total seluruh pendapatan dari pajak hotel, rumah makan serta restoran pada tahun 2016 yaitu sebesar 15.923,78 juta rupiah, sedangkan pada tahun 2017 sebesar 17.982,27 juta rupiah, 2.058,49 juta lebih besar dari tahun sebelumnya. Realisasi Pendapatan Asli Daerah (PAD) pada tahun 2016 sebesar 529.050,29 juta rupiah, sedangkan Realisasi Pendapatan Asli Daerah (PAD) Kabupaten Cirebon pada tahun 2017 sebesar 779.337,85 juta rupiah. Untuk melihat kontribusi hotel, rumah makan serta hiburan yang dijadikan sebagai indikator sektor pariwisata suatu daerah maka digunakan perhitungan sebagai berikut:

$$
\begin{gathered}
\text { Kontribusi Pariwisata }=\frac{\text { Pendapatan sektor pariwisata }}{P A D} \times 100 \% \\
\text { Kontribusi } 2016=\frac{15.923,78 \text { juta rupiah }}{529.050,29 \text { juta rupiah }} \times 100 \%=3 \% \\
\text { Kontribusi } 2017=\frac{17.982,27 \text { juta rupiah }}{779.337,85 \text { juta rupiah }} \times 100 \%=2,3 \%
\end{gathered}
$$

Berdasarkan hasil pengolahan di atas dapat terlihat bahwa sektor pariwisata berkontribusi sebesar 3\% dari total keseluruhan PAD pada tahun 2016, kemudian menurun pada tahun 2017 yaitu hanya sebesar 2,3\% meskipun jumlah pendapatan pajak dari sektor pariwisata pada tahun tersebut naik ternyata tidak banyak mempengaruhi PAD pada tahun tersebut yang sebenarnya juga naik.

\section{Kunjungan Wisatawan Kabupaten Cirebon 2016-2017}

Berdasarkan data dari Dinas Pemuda, Pariwisarta dan Olahraga (Disbudparpora) Kabupaten Cirebon tahun 2016-2017 jumlah kunjungan wisatawan Kabupaten Cirebon terus mengalami kenaikan. Berikut merupakan data kunjungan tersebut:

a. Kunjungan Hotel

Tabel

Jumlah Kunjungan Wisatawan Pada Hotel di Kabupaten Cirebon 20162017 (orang)

\begin{tabular}{|l|l|r|r|}
\hline & Nama Hotel & $\mathbf{2 0 1 6}$ & $\mathbf{2 0 1 7}$ \\
\hline & Aston & 62.358 & 90.013 \\
\hline & Apita & 2.854 & 5.150 \\
\hline & Sutan Raja & 20.788 & 20.444 \\
\hline & Omega & 160 & - \\
\hline
\end{tabular}


INKLUSIF Vol 3. No. 2 Desember 2018

\begin{tabular}{|l|l|r|r|}
\hline & Patra Jasa & 9.901 & - \\
\hline & Fantasia & 5.722 & 5.770 \\
\hline & Patapan Jaya & 3.085 & 3.052 \\
\hline & Putra Tidar Jaya & 3.774 & 3.001 \\
\hline & Puri Pesona & 1.199 & 1.213 \\
\hline & Lavender & 1.840 & 2.054 \\
\hline & Suka Hati & 853 & 1.735 \\
\hline & Roslita Sari & 11.700 & 12.394 \\
\hline & Bagus Inn & 1.270 & $256^{*}$ \\
\hline & Srikandi & 7.604 & 7.015 \\
\hline & Cirebon Indah & 5.093 & 5.206 \\
\hline & Viktori & 1.048 & 1.302 \\
\hline & Qintani & 2.625 & 1.431 \\
\hline & Koening & 2.994 & $2.482^{*}$ \\
\hline & Smile & 638 & 1.061 \\
\hline & Santun & 957 & $861^{*}$ \\
\hline & Verse & - & 19.479 \\
\hline & Jumlah & $\mathbf{1 4 8 . 8 5 6}$ & $\mathbf{1 8 0 . 6 2 7}$ \\
\hline
\end{tabular}

Sumber: Disbudparpora Kabupaten Cirebon

*tidak genap 12 bulan (satu tahun)

Berdasarkan tabel diatas dapat dilihat bahwa jumlah kunjungan hotel di Kabupaten Cirebon pada tahun 2017 naik dari tahun 2016, tahun 2016 sebanyak 148.856 pengunjung sedangkan tahun 2017 sebanyak 180.627 pengunjung. Pengunjung hotel terbanyak pada tahun 2016 yaitu hotel Aston sebanyak 62.358 pengunjung sedangkan pengunjung hotel paling sedikit yaitu hotel omega yaitu sebanyak 160 pengunjung. Sama halnya dengan tahun 2016, pada tahun 2017 pengunjung hotel terbanyak yaitu hotel Aston, yaitu sebanyak 90.013 pengunjung, selain wisatawan lokal pengunjung pada hotel Aston juga merupakan wisatawan mancanegara, total jumlah pengunjung wisatawan mancanegara pada hotel Aston adalah 5.986 pengunjung pada tahun 2016 dan 3.285 pengunjung pada tahun 2017.

Pada tahun 2016 terdapat hotel yang mulai beroprasi dengan jumlah pengunjung yang langsung meningkat pada tahun 2017 sebanyak 19.479 pengunjung, yaitu hotel Verse. Hotel yang terletak di Jalan Tuparev ini dioperasikan oleh Verse Hotels yang saat ini juga mengoperasikan Hotel Verse Lite Pembangunan Jakarta dan Hotel Oak Tree Urban Mahakam Jakarta. ${ }^{12}$ Hotel ini memiliki 116 kamar dengan tiga tipe. Yaitu Superior, Deluxe dan Eksekutif. Setiap kamar dilengkapi dengan tempat tidur berstandar internasional, pendingin ruangan, jaringan internet gratis, perlengkapan mandi, televisi dengan saluran nasional dan internasional, serta alat pembuat teh dan kopi di dalam kamar.

Berdasarakan hasil wawancara dengan salah satu anggota Bidang Pariwisata pada Disbudparpora Kabupaten Cirebon, Bapak Cecep, bahwa hotel yang layak untuk

\footnotetext{
${ }^{12}$ Sisca Harum, “Hotel Verse: Akomodasi Nyaman Untuk Bisnis Dan Liburan,” 2017, marketplus.co.id.
} 
dijadikan salah satau destinasi wisata halal adalah hotel hotel santun dan hotel koening. ${ }^{13}$ Hotel santun dibilang layak karena hotel tersebut sebenarnya dekat dengan salah satu pondok pesantren, yaitu Pesantren al-Bahjah. Target pasar mereka adalah para orang tua/wali yang mengunjungi anaknya maupun orang-orang yang mengikuti kajian pada PP al-Bahjah, bahkan hotel ini disebut sebagai Hotel Santun Syariah. Sedangkan hotel Koening, menurut beliau layak dijadikan salah satu akomodasi pada destinasi wisata halal karena fasilitas yang tersedia cukup memadai sebagai salah satu hotel yang sesuai dengan aturan islam.

\section{b. Kunjungan Museum dan Event}

Wisatawan yang datang ke suatu daerah memiliki tujuan untuk mencari tahu bagaiamana dan apa saja mueseum atau event yang terdapat di daerah tujuannya. Berdasarakan data yang diperoleh, berikut merupakan data kunjungan mueseum dan event di kabupaten Cirebon:

Tabel

Jumlah Kunjungan Museum dan Event di Kabupaten Cirebon 2016-

2017

\begin{tabular}{|c|c|c|}
\hline Museum \& Event & 2016 & 2017 \\
\hline $\begin{array}{ll}\text { Museum } & \text { Pangeran } \\
\text { Cakrabuana } & \end{array}$ & 1.433 & 1.113 \\
\hline Event Caruban Travelmart & 200 & 350 \\
\hline Event Caruban Festival & 30.000 & 40.000 \\
\hline Jumlah & 31.633 & 41.463 \\
\hline
\end{tabular}

Sumber: Disbudparpora Kabupaten Cirebon

Berdasarkan jumlah pengunjung pada event di atas dapat terlihat bahwa pengunjung mengalami peningkatan dari tahun 2016 ke 2017 naik 31\% dari 31.633 pengunjung menjadi 41.463 pengunjung. Kenaikan jumlah pengunjung mejadi salah satu indikator untuk terus meningkatkan ekonomi daerah, terutama melalui wisata halal.

Berdasarkan keterangan salah satu pengelola museum Pangeran Cakrabuana, keberadaan museum ini kurang mendapat perhatian dari masyarakat sekitar. Museuem ini terdiri dari dua lantai yang terletak satu komple dengan Disbudparpora Kabupaten Cirebon. Kurangnya SDM yang kompeten dalam bidang sejarah di Kabupaten Cirebon juga merupakan salah satu kendala kenapa museum ini kurang berkembang pesat. Padahal isi dari muesem tersebut menyimpan banyak topeng khas Cirebon, berbagai baju adat, alat-alat kesenian, kaligrafi serta pewayangan.

${ }^{13}$ Cecep, “Hasil Wawancara Dengan Anggota Bidang Pariwisata Disbupdparpora Kabupaten Cirebon,” 2018. 


\section{c. Kunjungan Obyek Wisata}

Obyek wisata merupakan salah satu magnet terbesar bagi wisatawan, keberadaanya memiliki nilai sebagai salah satu potensi ekonomi yang dapat terus ditingkatkan dengan kerjasama antara pemerintah, masyarakat serta pengelola obyek wisata tersebut. Berikut merupakan jumlah kujungan wisatawan pada obyek wisata di Kabupaten Cirebon:

Tabel

Jumlah Kunjungan Obyek Wisatadi Kabupaten Cirebon 2016-2017

\begin{tabular}{|l|l|r|r|}
\hline \multicolumn{1}{|c|}{ Nama Obyek Wisata } & \multicolumn{1}{c|}{$\mathbf{2 0 1 6}$} & \multicolumn{1}{c|}{$\mathbf{2 0 1 7}$} \\
\hline & Obyek Sunan Gunung Jati & 184.795 & 228.491 \\
\hline & Syekh Magelung sakti & 13.124 & 19.714 \\
\hline Plangon & 5.000 & 4.948 \\
\hline & Talun & 5.572 & 79.370 \\
\hline Banyu Panas & 235.427 & 141.492 \\
\hline & Belawa & 3.675 & 720 \\
\hline Ki Buyut Trusmi & 3.023 & 3.439 \\
\hline Nyi Mas Gandasari & 4.233 & 3.648 \\
\hline & Setu patok & 2.720 & 4.529 \\
\hline & Cimandung & 447 & 4.460 \\
\hline & Pasir Waled Adjimut & 631 & 690 \\
\hline & & 458.647 & 491.501 \\
\hline
\end{tabular}

Sumber: Disbudparpora Kabupaten Cirebon

Berdasarkan tabel di atas dapat dilihat bahwa jumlah kunjungan mengalami kenaikan dari tahun 2016 sebanyak 458.647 pengunjung dan tahun 2017 sebanyak 491.501 pengunjung. Kenaikan jumlah pengunjung menjadi salah satu potensi ekonomi yang dapat dikembangkan terlebih jika dipadukan dengan adanya paket wisata halal di Kabupaten Cirebon.

\section{Batik Trusmi, Makam Sunan Gunung Jati dan Empal Gentong}

\section{a. Batik Trusmi}

Batik merupakan salah satu ciri khas daerah. Kabupaten Cirebon mempunyai wisata belanja batik. Batik yang paling terkenal adalah batik mega mendung, ini merupakan corak khusus batik cirebon. Sentra batik yang paling terkenal adalah Trusmi, Trusmi merupakan salah satu desa di Kabupaten Cirebon yang paling terkenal dengan kerajinan batiknya. Pada tahun 2012, Kabupaten Cirebon memiliki usaha batik sebanyak 404 unit dan tahun 2013 menjadi 521 unit. Jumlah usaha sebanyak itu mampu menyerap tenaga kerja sebanyak \pm 3.691 orang pada 
tahun 2012 dan tahun 2013 jumlahnya bertambah menjadi \pm 4.462 orang. Kapasitas produksi industri batik sebesar \pm 19.043 kodi pada tahun 2012 dan jumlahnya meningkat menjadi 23.023 kodi pada tahun 2012. Nilai produksi industri ini sebesar $\mathrm{Rp} 65.560 .443 .000,00 .{ }^{14}$ Wilayah pemasaran produk kerajinan batik adalah dalam negeri dan luar negeri. Negara tujuan pemasaran keluar negeri adalah Jepang, Brunei, dan Malaysia. Sentra kerajinan batik di Kecamatan Plered berada di Desa Trusmi Kulon, Trusmi Wetan, dan Panembahan. Sementara, sentra kerajinan batik di Kecamatan Tengah Tani berada di Desa Kalibaru, dan Kalitengah.

\section{b. Makam Sunan Gunung Jati}

Makam Sunan Gunung Jati merupakan salah satu obyek wisata yang juga menjadi ciri khas Kabupaten Cirebon, mengingat Sunan Gunung Jati merupakan salah satu dari sembilan wali sebagai penyiar agama Islam di Indonesia, khususnya tanah Jawa. Pada tahun 2017 ada 228.491 pengunjung yang mendatangi obyek wisata tersebut. Obyek wisata Makam Sunan Gunung Jati merupakan salah satu dari beberapa makam yang menjadikan cirebon sebagai salah satu wilayah destinasi ziarah dan cagar budaya sesuai dengan ketetapan gubernur Jawa Barat.

Berdasarkan hasil penelitian Ali, yang melakukan penelitian mengenai salah satu tradisi kliwonan di Gunung Jati satu bulan sekali, dapat terlihat bahwa adanya acara tersebut merupakan peluang melimpahnya rizki bagi masyarakat sekitar. ${ }^{15}$ Beberapa barang banyak dipasarkan dalam acara kliwonan tersebut seperti buku historis Gunung Jati, tasbih, wewangian, asesoris Islam, sajadah, kerudung, kemenyan, kopiah, poster wali, kaligrafi, pakaian jadi, sepatu dan lain sebagainya.

Penulis berkesempatan untuk mengunjungi salah satu objek religi yang terkenal, yaitu Makam Sunan Gunung Jati. Berdasarkan keterangan kuncen makam ini ramai setiap harinya terlebih ketika malam jum'at kliwon. Pengunjung yang datang tidak hanya penduduk sekitar tetapi dari berbagai wilayah di Indonesia (luar pulau Jawa).

Banyak pedagang yang menjajakan jualannya di sekitar makam, baik pedagang kaki lima maupun yang menetap (biasanya turun temurun). Pedagang kaki lima akan dipungut biaya keberseihan besar Rp 2.000,00 setiap harinya, sedangkan pedagang yang menetap biasanya perminggu/perdua minggu. Berbagai makanan maupun oleh-oleh khas Cirebon dijajakan disana dengan harga relatif dari Rp 3.000,00 (untuk makanan biasanya) - Rp 200.000,00 (untuk pakaian).

\footnotetext{
${ }^{14}$ Bappelitbangda Kabupaten Cirebon, "Rencana Pembangunan Jangka Menengah Daerah (RPJMD) Kabupaten Cirebon 2014-2019." 45-46.

${ }^{15}$ Abdullah Ali, Tradisi Kliwonan Gunung Jati: Model Wisata Religi Di Kabupaten Cirebon (Cirebon: Pemerintah Kabupaten Cirebon, 2007). 81.
} 
INKLUSIF Vol 3. No. 2 Desember 2018

\section{c. Empal Gentong}

Empal gentong merupakan salah satu kuliner paling khas yang ada di Kabupaten Cirebon. Wisata kuliner empal gentong hampir ditemui di setiap daerah di Cirebon, hampir 40 kecamatan di Cirebon. Ada lima tempat yang terkenal dengan empal gentongnya yaitu empal gentong $\mathrm{H}$. Apud, Amarta, Krucuk, Hj. Dian, serta Bu Darma. ${ }^{16}$ Empal gentong sendiri adalah olahan daging sapi menyerupai gulai. Kuliner ini dimasak menggunakan gentong besar yang terbuat dari tanah liat.

Wisata kuliner ini merupakan salah satu potensi bagi masyarakat Kabupaten Cirebon yang memiliki potensi membuat olahan kuliner khas tersebut, sehingga kemanapun wisatawan melakukan destinasi di Kabupaten Cirebon terdapat empal gentong. Empal gentong pun patut dijadikan salah satu makanan yang dikenalkan pada kancah global agar pangsa pasarnya semakin naik.

Khasnya empal gentong dapat dijadikan salah satu indikator penarik wisata halal di Kabupaten Cirebon. Dengan terkenalnya kuliner tersebut, wisatawan akan tertarik untuk 'harus mencicipi' kuliner tersebut ketika mengunjungi Kabupaten Cirebon. Ketika wisatawan sudah tahu maka sistem mouth of mouth akan berjalan dengan sendirinya.

Pada tanggal 19 September 2018 penulis berkesempatan untuk mengunjungi salah satu kuliner empal gentong di Kabupaten Cirebon, yaitu empal gentong $\mathrm{H}$. Apud, dimana penulis berkesempatan langsung untuk mewawancara beliau. Berdasarakan keterangan beliau empal gentongnya tersebut mulai didirikan tahun 1994 atau sudah sekitar 24 tahun lamanya. Awalnya beliau berjualan kue, tapi karena hasil tidak menentu beliau mulai berjualan empal gentong secara berkeliling, hingga pada tahun 2002 beliau memutuskan untuk menentap (tidak berkeliling). Pelanggan yang sudah mengetahui ciri khas empal tersebut semakin banyak berdatangan ke kedai beliau, terlebih ketika pada tahun 2010 Presiden SBY mulai mewajibkan batik bagi PNS maupun pelajar, para pengunjung yang berbelanja batik ke Kabupaten Cirebon (Trusmi) biasanya singgah di Empal Gentong ini. Selain empal gentong di tempat ini terdapat empal asem yang juga terkenal di Kabupaten Cirebon. Satu porsi empal gentong dihargai Rp 22.000,00 (sebelum pajak), sate kambing Rp 40.000,00 (sebelum pajak), nasi Rp 5.000,00 (sebelum pajak). Pemerintah daerah Kabupaten Cirebon bidang dinas pendapatan biasanya tiap minggu berkunjung ke kedai beliau untuk memunguti pajak restoran.

Dalam satu hari kerja, terjual sebanyak 800-900 porsi. Sedangkan akhir pekan atau liburan bisa lebih dari 1.300 porsi. Empal gentong H.Apud terdapat 3 cabang yaitu di Tengah Tani (pusatnya), Jl. Tuparev serta di Plered.

Mengenai sertifikasi halal, empal ini sudah mendapat sertifikat halal dari MUI, menurut beliau halal menjadi indikator yang penting karena konsumen harus merasa terjamin bahwa apa yang dimakan sudah jelas halalnya. Daging yang beliau gunakan

16 Muhammad Irzal Adiakurnia, "5 Empal Gentong Khas Cirebon Yang Harus Anda Coba," 2017, n.d., https://travel.kompas.com/read/2017/12/23/150200927/5-empal-gentong-khas-cirebon-yang-harus-anda-coba. 
didapat dari pemasok khusus (tidak menyembelih sendiri) dengan alasan banyak yang mubadzir jika menyembelih sendiri karena yang digunakan adalah daging dan jeroan saja. Presiden SBY juga Jokowi sudah pernah berkunjung di kedai beliau, sebelum kedatangan presiden tim kesehatan presiden biasanya akan memastikan kebersihan dan kesehatan makanan seminggu sebelumnya, baik itu nasi maupun empal dan sate yang akan dikonsumsi presiden.

\section{PENUTUP}

Kondisi ekonomi di Kabupaten Cirebon dapat dilihat dari nilai Pendapatan Asli Daerah (PAD). PAD Kabupaten Cirebon pada tahun 2017 sebesar 779.337,85 juta rupiah, dengan tingkat kemandirian fiskal sebesar $105 \%$ sehingga memiliki pola hubungan delegatif.

Sektor Pariwisata di Kabupaten Cirebon pada tahun 2017 berpengaruh sebesar 2.3\%. Tahun 2017 kunjungan wisatawan meningkat dari tahun sebelumnya, yaitu 713.591 orang. Kenaikan kunjungan wisatawan menunjukkan bahwa Kabupaten Cirebon memiliki magnet bagi para wisatawan yang ingin berkunjung ke Kabupaten Cirebon. Daya tarik yang dimiliki berupa seni budaya, objek wisata, kuliner, serta sarana wisatanya. Peningkatan pengunjung sebagai lahan yang potensial sebagai salah satu pilar ekonomi daerah, mengingat pariwisata adalah salah satu kebutuhan yang tidak lepas dalam hidup setiap orang

Potensi ekonomi pada wisata halal di Kabupaten Cirebon dapat dilihat dari wisata ziarah, kuliner, budaya yang dapat terus dikembangkan menjadi suatu potensi ekonomi yang menggiurkan terlebih dangan adanya dukungan pemerintah serta elemenlainnya seperti akademisi maupun praktisi.

\section{DAFTAR PUSTAKA}

Adiakurnia, Muhammad Irzal. "5 Empal Gentong Khas Cirebon Yang Harus Anda Coba." 2017, n.d. https://travel.kompas.com/read/2017/12/23/150200927/5-empal-gentong-khas-cirebonyang-harus-anda-coba.

Ali, Abdullah. Tradisi Kliwonan Gunung Jati: Model Wisata Religi Di Kabupaten Cirebon. Cirebon: Pemerintah Kabupaten Cirebon, 2007.

Arikunto, Suharsimi. Prosedur Penelitian: Suatu Pendekatan Praktek. Jakarta: Rineka Cipta, 2002.

Bappelitbangda Kabupaten Cirebon. "Rencana Pembangunan Jangka Menengah Daerah (RPJMD) Kabupaten Cirebon 2014-2019," n.d.

Bungin, Burhan. Metodologi Penelitian Sosial:Format-Format Kuantitatif. Surabaya: Airlangga University Press, 2003.

Cecep. "Hasil Wawancara Dengan Anggota Bidang Pariwisata Disbupdparpora Kabupaten Cirebon," 2018.

Edwin. "Hasil Wawancara Dengan Kepala Bidang Pariwisata Disbudparpora Kabupaten Cirebon," 2018.

Guntur Sakti. "Siaran Pers: Indonesia Berada Di Peringkat 2 Global Muslim Travel Index 2018," 2018. kemenpar.go.id.

- - " "Siaran Pers : Menpar: Berada Di Peringkat I GMTI, Wisata Halal Indonesia Akan Mudah Rebut Pasar Global," 2018. kemenpar.go.id.

Harum, Sisca. "Hotel Verse: Akomodasi Nyaman Untuk Bisnis Dan Liburan," 2017. marketplus.co.id. 
Jaelani, Aan. "Event and Festival in Cirebon: Review of Shariah Marketing Mix." Management, no. 6461 (2007). https://doi.org/10.1111/j.1574-0862.2010.00507.x/abstract.

- - . "Islamic Tourism Development In Cirebon: The Study Heritage Tourism in Islamic Economic Perspective," 2016, 1-24. http://www.researcherid.com/rid/D-6905-2016.

Kemenparekraf. "Kajian Pengembangan Wisata Syariah," 2015.

Kurnia, Muhamad Irzhal Adia. "Tak Hanya Religi, Ini Wisata Menarik Lainnya Di Kabupaten Cirebon," https://travel.kompas.com/read/2017/05/13/120700727/tak.hanya.religi.ini.wisata.menarik .lainnya.di.kabupaten.cirebon.

Kurniawan Gilang Widagyo. "Analisis Pasar Pariwisata Halal Di Indonesia." The Journal of Tauhidinomics, 2015.

Marzuki. Metodologi Riset. Yogyakarta: BPFE UII, 1995.

Moleong, Lexy J. Metodologi Penelitian Kuantitatif. Bandung: PT Remaja Rosdakarya, 2005.

Sugiyono. Metode Penelitian Kuantitatif, Kualitatif Dan R\&D. Bandung: Alfabeta, 2017. 